${ }^{1}$ Московский государственный медико-

стоматологический университет им. А.И. Евдокимова

${ }^{2}$ Научно-

исследовательский институт

скорой помощи им. Н.В. Склифосовского

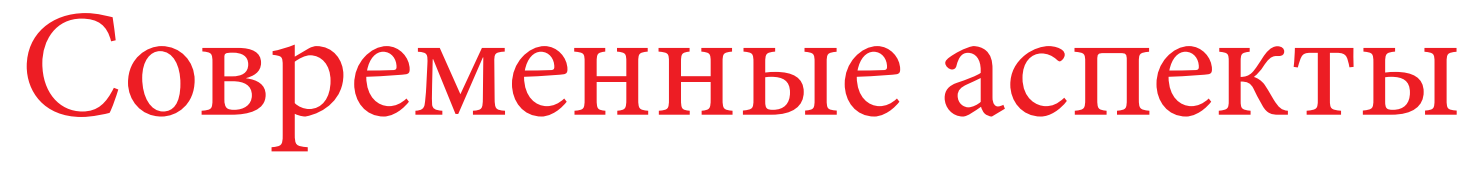
диагНостики

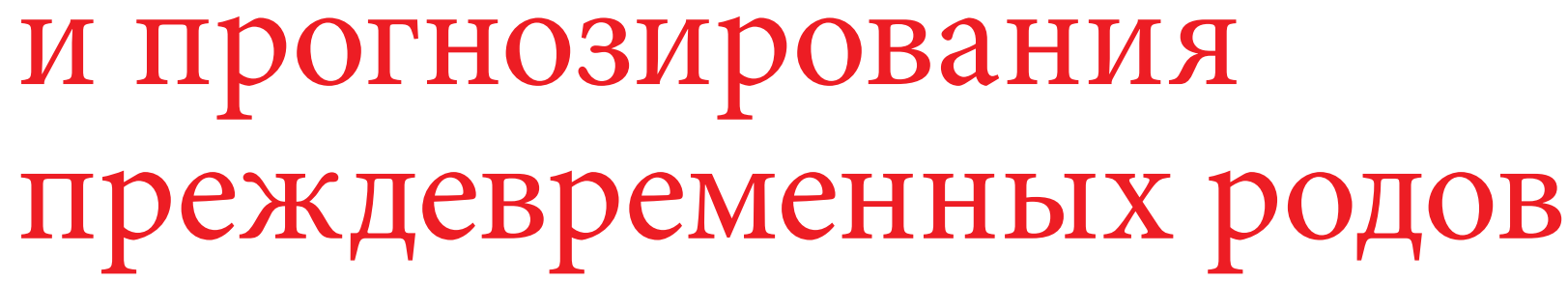

М.А. Такоева ${ }^{1}$, С.Г. Цахилова, д.м.н., проф. ${ }^{1}$, В.С. Мурадова ${ }^{1}$, М.А. Еременко ${ }^{2}$

Адрес для переписки: Марина Аркадьевна Такоева, moraova.marina@yandex.ru

Для цитирования: Такоева М.А., Цахилова С.Г., Мурадова В.С., Еременко М.А. Современные аспекты диагностики и прогнозирования преждевременных родов // Эффективная фармакотерапия. 2021. Т. 17. № 19. С. 16-19.

DOI 10.33978/2307-3586-2021-17-19-16-19

В статье представлены современные методы диагностики и прогнозирования преждевременных родов, используемые акушерами-гинекологами в практической деятельности. Ранняя диагностика и прогнозирование, основанные на определении плацентарного альфа-микроглобулина 1 во влагалищном секрете, позволяют снизить частоту преждевременных родов, а также количество неоправданных госпитализаций и медицинских вмешательств.

Ключевые слова: преждевременные роды, плачентарный альфа-микроглобулин 1 , фетальный фибронектин, иервиковагинальная жидкость

\begin{abstract}
A ктуальность проблемы преждевременных родов (ПР) обусловлена тем, что именно недоношенные дети определяют уровень перинатальной смертности (70-75\% в структуре перинатальной смертности) и неонатальной заболеваемости, а также представляют группу риска в отношении долгосрочной детской неврологической инвалидности. Согласно последним данным, в европейских странах частота ПР составляет 5-9\%, в США - в среднем $12-13 \%$, в России - около $7-12 \%$ в зависимости от региона. Несмотря на достижения современной медицины, данные показатели не снижаются [1-3].

Преждевременные роды - роды, наступившие при сроке гестации от 22 недель (154 дня) до 37 (259 дней) начиная с первого дня последней менструации при регулярном менструальном цикле и массе плода свыше 500 г.
\end{abstract}

В основе ПР могут лежать иммунологические и генетические, социально-биологические факторы, а также инфекции, коагулопатии, гормональные нарушения и т.д.

Так, в ряде работ установлена прямая связь между ПР и группой анамнестических факторов, таких как высокий паритет, аборт и привычная потеря беременности.

Чаще ПР обусловлены истмико-цервикальной недостаточностью. На ее долю во втором триместре приходится около $40 \%$ случаев, в третьем до $35 \%$ [4].

Инфицирование во время беременности токсоплазмой, цитомегаловирусом, вирусом краснухи или микоплазмой вызывает пороки развития, часто несовместимые с жизнью плода. Однако недавние исследования свидетельствуют, что внутриамниотическое воспаление, связанное с ПР, 
может иметь место в отсутствие инфекционных агентов, что указывает на участие стерильного внутриамниотического воспаления [5].

Значимая роль в наступлении ПР отводится персистенции условно-патогенной микрофлоры в эндометрии вне беременности, которая, по мнению ряда авторов, становится причиной прерывания беременности на поздних сроках у 67,7\% пациенток.

Немаловажное значение придается аутоиммунным процессам, которые прежде всего направлены против материнских клеток и тканей и влияние которых на плод вторично. К подобным реакциям можно отнести антифосфолипидный синдром, который характеризуется тромботическим поражением сосудов, в том числе сосудов плаценты, что обусловливает нарушение маточно-плацентарного кровообращения и, как следствие, привычное невынашивание беременности, задержку развития плода, его внутриутробную гибель $[6,7]$.

В настоящее время в связи с развитием репродуктивных технологий ежегодно увеличивается число беременностей и родов, наступивших после экстракорпорального оплодотворения (ЭКО). Так, в развитых странах этот показатель достигает 4,1\%. Женщины, у которых беременность наступила в результате применения методов вспомогательных репродуктивных технологий, относятся к группе высокого риска. По данным различных исследований, частота самопроизвольных абортов у них достигает 44\%, ПР - 37\%. Основными факторами риска ПР при индуцированной беременности являются поздний репродуктивный возраст, отягощенный акушерско-гинекологический и соматический анамнез и многоплодие. В российских исследованиях показано, что ПР наступают более чем у 26-30\% женщин после ЭКО с донацией ооцитов и почти у $22 \%$ женщин, рожающих по программе суррогатного материнства. Чаще прерывается многоплодная беременность, что увеличивает риск неблагоприятных перинатальных исходов. Это объясняется физиологическими и анатомическими особенностями (ограниченность объема матки, снижение запирательных функций шейки матки (ШМ)), иммунодефицитом беременных с многоплодием. Последние российские данные свидетельствуют, что при индуцированном многоплодии ПР наблюдаются в $86,3 \%$ случаев [8-13].

С учетом сложившейся демографической ситуации в России прогнозирование начала ПР представляет важную медико-социальную проблему, для решения которой необходимо понимание их патогенеза и наличие соответствующих диагностических методов.

Современные методы прогнозирования спонтанных ПР можно разделить на три категории:

1) оценка анамнестических факторов риска;

2) цервикометрия;

3) анализ биохимических маркеров.
В российских исследованиях показано, что преждевременные роды наступают более чем у 26-30\% женщин после ЭКО с донацией ооцитов и почти у 22\% женщин, рожающих по программе суррогатного материнства. Чаще прерывается многоплодная беременность. Это объясняется физиологическими и анатомическими особенностями (ограниченность объема матки, снижение запирательных функций шейки матки), иммунодефицитом беременных

\section{с многоплодием}

По мнению ряда авторов, дополнительным достоверным критерием спонтанных ПР является симптом «воронки» - V-образная деформация внутреннего зева с пролабированием нижнего полюса плодного пузыря в ШМ, приводящая к укорочению ее функциональной длины. Данный симптом отмечается у $10 \%$ беременных без факторов риска ПР и 20-25\% из группы высокого риска [14].

Выраженный симптом «воронки», выявленный до 22-й недели беременности, ассоциируется с ПР в $50 \%$ случаев.

Согласно результатам ретроспективного сравнительного исследования, у женщин с воронкообразной формой укороченной ШМ даже при использовании пессария доктора Арабин или серкляжа по Макдональду частота ПР значительно выше, чем у пациенток без симптома «воронки» [14].

Наиболее значимым ультразвуковым маркером высокого риска ПР служит длина ШМ. При соблюдении техники исследования эффективность в серии повторных измерений разными наблюдателями достигает $90 \%$.

Длина ШМ у беременных на сроке гестации 14-24 недели составляет от 25 до 50 мм. Длина ШМ менее 25 мм по результатам ультразвуковой цервикометрии является достоверным предиктором спонтанных ПР. У женщин с повышенным риском невынашивания беременности укорочение ШМ менее 25 мм на 14-18-й неделе имеет прогностическую ценность в отношении ПР на сроке менее 35 недель в 70\% случаев, на 18-22-й неделе только в $40 \%$. Среди пациенток с одноплодной беременностью и отсутствием в анамнезе ПР следует выделить группу женщин с очень короткой ШМ ( $\leq 11$ мм). У таких женщин высок риск бессимптомной дилатации ШМ и неблагоприятного перинатального исхода. Укорочение ШМ по результатам трансвагинальной цервикометрии служит достоверным предиктором ПР с чувстви- 
тельностью до 75\% и специфичностью 80\%. Установлено, что у $77 \%$ женщин с длиной ШМ $\leq 11$ мм ПР происходят ранее 37 недель, причем у 63\% - до 34-й недели беременности.

Дополнительным ультразвуковым прогностическим маркером ПР во втором триместре беременности является маточно-цервикальный угол. Под действием силы тяжести беременная матка смещается в сторону ШМ в зависимости от угла наклона. При остром угле наклона шеечный канал закрывается, при тупом приоткрывается. Чувствительность метода - 81,3\%, специфичность $83,1 \%[15-17]$.

Цервиковагинальная жидкость (CVF) имеет значение для наблюдения за здоровьем матери и плода во время беременности. Это сложная смесь секретов влагалища, эндоцервикса, децидуального эндометрия и амниотической жидкости. Цервиковагинальная жидкость легкодоступна для исследования, поскольку методы ее сбора малоинвазивные, безболезненные и безопасные в отличие от методов сбора амниотической жидкости.

К настоящему моменту проведено множество исследований разных биохимических маркеров CVF.

Для прогнозирования ПР в клинической практике используются три биомаркерных теста: фетальный фибронектин (fFN), белок, связывающий инсулиноподобные факторы роста 1 (IGFBP-1), и плацентарный альфа-микроглобулин 1 (PAMG-1). Фетальный фибронектин представляет собой внеклеточный матриксный гликопротеин. Его продуцируют амниоциты и клетки цитотрофобласта, находящегося на границе околоплодных оболочек между хорионом и децидуальными клетками, где он концентрируется. В норме fFN содержится в очень низких концентрациях в CVF. Уровень fFN более 50 нг/мл с 22-й недели беременности ассоциируется с высоким риском спонтанных ПР. Однако определение fFN в CVF имеет ограниченное применение из-за относительно низкой специфичности и прогностической ценности. Как показал метаанализ, проведение теста на fFN при одноплодной беременности не улучшает перинатальные исходы, но способствует увеличению затрат [18].

Еще один экспресс-тест, используемый в качестве предиктора ПР, основан на иммунохроматографическом определении фосфорилированной формы протеина 1. Его диагностическая чувст- вительность - 88,9\%, специфичность - $100 \%$. Фосфорилированный протеин 1, связывающий IGFBP-1, синтезируется децидуальными клетками. Отрицательный результат экспресс-теста указывает на низкий риск ПР в течение семи дней после исследования. Чувствительность данного теста достигает 89\%, специфичность - 94\%, положительная и отрицательная прогностическая ценность - 94 и 89\% соответственно [18-20].

На сегодняшний день научный и клинический интерес представляет тест, основанный на выявлении PAMG-1 во влагалищном секрете. PAMG-1 представляет собой низкомолекулярный белок весом $20000 \pm 2000$ Да, который в норме содержится в амниотической жидкости, эндометрии, гранулоцитах, ворсинчатой и децидуальной тканях. Основной функцией PAMG-1 является регуляция митогенной и метаболической активности IGFBP-1. Появление PAMG-1 в содержимом влагалища объясняется двумя механизмами:

1) деградацией экстрацеллюлярного матрикса плодных оболочек, связанной с воспалительным процессом, как правило обусловленным инфекцией, что является одной из основных причин ПР;

2) транссудацией белка сквозь поры плодных оболочек во время маточных сокращений.

Согласно результатам зарубежных исследований, положительная прогностическая ценность теста на PAMG-1 у беременных с длиной ШМ 15-30 мм в течение семи дней составляет 77\%, отрицательная прогностическая ценность в течение 14 дней - 93-100\%. Отрицательный результат теста указывает на низкий риск спонтанных ПР в течение 7-14 дней и тем самым определяет выбор терапии. В подобной ситуации стандартная терапия (профилактика респираторного дистресс-синдрома и токолиз) не требуется, что позволяет избежать госпитализации и неоправданной медикаментозной терапии в 71 и даже 91\% случаев [21].

Таким образом, совершенствование методов ранней диагностики и прогнозирования ПР призвано решить проблему невынашивания беременности, обеспечить индивидуализированный подход к профилактике ПР и своевременное начало регламентированной терапии при необходимости, уменьшить экономическую нагрузку на учреждения за счет снижения количества неоправданных госпитализаций и медицинских вмешательств.

\section{Литература}

1. Сухих Г.Т., Байбарина Е.Н., Шувалова М.П., Письменская Т.В. Российские тенденции снижения перинатальных потерь с учетом перехода на международные критерии регистрации рождения детей // Акушерство и гинекология. 2013. № 12. C. 79-85.

2. Menon R. Oxidative stress damage as a detrimental factor in preterm birth pathology // Front. Immunol. 2014. Vol. 12. № 5 . P. 567. 
3. Сухих Г.Т., Вартапетова Н.В. Преждевременные роды. Клинический протокол. Научный центр акушерства, гинекологии и перинатологии им. В.И. Кулакова, 2011.

4. Хапова Т.В., Оленев А.В., Выхристюк Ю.В. Преждевременные роды, факторы риска, прогнозирование // Вестник Российского университета дружбы народов. 2016. № 2. С. 208-211.

5. Romero R., Miranda J., Chaiworapongsa T. et al. Sterile intra-amniotic inflammation in asymptomatic patients with a sonographic short cervix: prevalence and clinical significance // J. Matern. Fetal Neonatal Med. 2015. Vol. 28 . № 11. P. 1343-1359.

6. Сидельникова В.М., Ледина А.В. Тактика ведения женщин с привычным невынашиванием беременности и хронической внутриутробной инфекцией // Гинекология. 2000. Т. 2. № 3. С. 72-76.

7. Сидельникова В.М., Сухих Г.Т. Невынашивание беременности. М.: МИА, 2010. С. 200-215.

8. Иакашвили С.Н., Самчук П.М. Особенности течения и исход одноплодной беременности, наступившей после экстракорпорального оплодотворения и переноса эмбриона, в зависимости от фактора бесплодия // Современные проблемы науки и образования: электронный научный журнал. 2017. № 3.

9. Мери Э. Ультразвуковая диагностика в акушерстве и гинекологии. Акушерство Т. 1 / пер. с англ. под общей ред. проф. А.И. Гуса. М.: МЕДпресс-информ, 2011.

10. Le Ray C., Scherier S., Anselem O. et al. Association between oocyte donation and maternal and perinatal outcomes in women aged 43 years or older // Hum. Reprod. 2012. Vol. 27. № 3. P. 896-901.

11. Трифонова Н.С., Жукова Е.В., Александров Л.С. и др. Течение беременности, родов и перинатальные исходы у суррогатных матерей // Вопросы гинекологии, акушерства и перинатологии. 2017. Т. 16. № 3. C. $6-13$.

12. Сичинава Л.Г., Панина О.Г., Гамсахурдиа К.Г. Дискордантный рост плодов у беременных с монохориальной двойней // Акушерство, гинекология и репродукция. 2015. Т. 9. № 1. С. 6-12.

13. Westerway S.C., Pedersen L.H., Hyett J. Cervical length measurement: comparison of transabdominal and transvaginal approach // Australas J. Ultrasound Med. 2015. Vol. 18. № 1. P. 19-26.

14. Астафьева О.В., Карякина И.В., Асланян Э.А., Михеева Н.В. Маточно-шеечный угол как дополнительный ультразвуковой маркер для прогнозирования преждевременных родов // Кубанский научный медицинский вестник. 2018. Т. 25. № 6. С. 26-31.

15. Болотских В.М., Борисова В.Ю. Роль определения биохимических маркеров и цервикометрии в диагностике угрожающих преждевременных родов // Акушерство и гинекология. 2015. № 2. С. 94-98.

16. Дикке Г.Б. Диагностика высокого риска преждевременных родов на основании биохимических тестов // Акушерство и гинекология. 2018. № 7. С. 108-112.

17. Kekki M., Kurki T., Kärkkäinen T. et al. Insulin-like growth factor-binding protein-1 in cervical secretion as a predictor of preterm delivery // Acta Obstet. Gynecol. Scand. 2001. Vol. 80. № 6. P. 546-551.

18. Sukchaya K., Phupong V. Comparative study of positive rate of placental alpha-microglobulin-1 test in pre-term pregnant women with and without uterine contraction // J. Obstet. Gynaecol. 2013. Vol. 33. № 6. P. 566-568.

19. Di Fabrizio L., Giardina I., Cetin I. et al. New methods for prediction of preterm birth: the PAMG-1 test // Minerva Ginecol. 2018. Vol. 70. № 5. P. 635-640.

20. Van Holsbeke C., Dam K., Staelens A. et al. Comparison of the fetal fibronectin (Rapid fFN) and placental alpha microglobulin-1 (PartoSure) tests for predicting imminent spontaneous preterm birth // Ultrasound Obstet. Gynecol. 2016. Vol. 48. № 1. P. 84.

21. Lotfi G., Faraz S., Nasir R. et al. Comparison of the effectiveness of a PAMG-1 test and standard clinical assessment in the prediction of preterm birth and reduction of unnecessary hospital admissions // J. Matern. Fetal Neonatal Med. 2009. Vol. 32. № 5. P. 793-797.

\section{Modern Concepts of Diagnosis and Prediction of Preterm Birth}

M.A. Takoyeva ${ }^{1}$, S.G. Tsakhilova, PhD, Prof. ${ }^{1}$, V.S. Muradova ${ }^{1}$, M.A. Yeremenko ${ }^{2}$

${ }^{1}$ A.I. Yevdokimov Moscow State University of Medicine and Dentistry

${ }^{2}$ Sklifosovsky Research Institute of Emergency Medicine

Contact person: Marina A. Takoyeva, moraova.marina@yandex.ru

The article presents modern methods of diagnosing and predicting preterm birth in the practice of an obstetrician-gynecologist. Early prediction and diagnosis of preterm birth, based on the determination of placental alpha macroglobulin 1 in vaginal secretions, will make it possible to reduce the incidence of preterm birth, as well as reduce the number of unnecessary hospitalizations and unnecessary medical interventions.

Key words: preterm birth, placental alpha-macroglobulin 1, fetal fibronectin, cervicovaginal fluid 